\title{
New Applications in Atom Probe Tomography
}

D.J. Larson ${ }^{1}$, J.W. Valley ${ }^{2}$, T. Ushikubo ${ }^{2}$, M.K. Miller ${ }^{3}$, H. Takamizawa ${ }^{4}$, Y. Shimizu ${ }^{4}$, L. M. Gordon $^{5}$, D. Joester ${ }^{5}$, A.D. Giddings ${ }^{1}$, D.A. Reinhard ${ }^{1}$, T.J. Prosa ${ }^{1}$, D.P. Olson ${ }^{1}$, D.F. Lawrence ${ }^{1}$, P.H. Clifton $^{1}$, R.M.Ulfig ${ }^{1}$, I.Y. Martin ${ }^{1}$, and T.F. Kelly ${ }^{1}$

${ }^{1}$ CAMECA Instruments Inc., 5500 Nobel Drive, Madison, WI 53711 USA

2 Department of Geoscience, University of Wisconsin, Madison, WI 53706 USA

${ }^{3}$ Oak Ridge National Laboratory, Oak Ridge, TN 37831-6139 USA

${ }^{4}$ Institute for Materials Research, Tohoku University, 311-1313 JAPAN

${ }^{5}$ Dept. of Materials Science \& Engineering, Northwestern University, Evanston, IL 60208 USA

Recent innovations in atom probe tomography (APT), including laser pulsed field evaporation and focused ion beam based sample preparation, have enabled a wide range of new applications [1]. This presentation is a survey of those advances which include metal-oxide-semiconductor (MOS) transistor dopant distribution analysis, geological dating of individual zircon crystals, quantum dot (QD) assembly in III-V multi-layer device structures, analysis of biological materials, and nanoscale phase behavior of metallic glasses.

MOS transistor variability has substantially increased due to the continuously decreasing feature size. APT provides elemental mapping to correlate electrical performance with dopant concentration, Fig. 1. For example, threshold voltage in $65 \mathrm{~nm}$-node n-MOS transistors has been positively correlated with the channel dopant concentration [2]. In geological materials, APT is now providing unique information for understanding the thermal history and mechanisms of mineral reaction, mineral exchange and radiation damage. In zircon crystals, precipitates containing $\mathrm{Y}$ and $\mathrm{Pb}$ are readily observed as shown in Fig. 2 . The ${ }^{207} \mathrm{~Pb} /{ }^{206} \mathrm{~Pb}$ ratios for nm-scale domains $\left(<2 \times 10^{4}\right.$ atoms $\mathrm{Pb}$ ) average $0.17 \pm 0.04$ and $0.43 \pm 0.14$ for 2.4 and 4.0 Ga zircons respectively [3], in agreement with SIMS ratios (0.1684 and 0.4269) derived from much larger analysis volumes (hundreds of $\mu \mathrm{m}^{3}\left(10^{-16} \mathrm{~m}^{3}\right)$ ). Quantum dots (QDs) are self-assembled nanostructures that have unique electronic properties determined by their physical structure. The high spatial resolution and chemical sensitivity of APT has made it possible to image QDs in InAs/GaAs multilayers [4]. The quantum dots (QDs) form into a pillar arrangement when the strain field from one QD layer influences the growth of subsequent layers, although the apparent helical distribution (Fig. 3) has never previously been reported. On the biological side, APT has revealed oriented collagen fibers in the dentin of elephant tusks. Fig. 4 is a mass spectrum from an apatite-derived calcium and phosphate species, additional inorganic substituents, and carbon/nitrogen containing fragments of organic macromolecules [5]. In metallic glass research, the glass forming ability of high Fe-content glasses for low-cost transformer applications is improved by small copper additions, Fig. 5. $\mathrm{Fe}_{76-}$ ${ }_{\mathrm{x}} \mathrm{C}_{7.0} \mathrm{Si}_{3.3} \mathrm{~B}_{5.0} \mathrm{P}_{8.7} \mathrm{Cu}_{0.7}$ glasses phase separates into $\alpha$-Fe precipitates, ultrafine spheroidal $\varepsilon$ - $\mathrm{Cu}$-rich precipitates, silicon-depleted $\mathrm{Fe}_{3}(\mathrm{P}, \mathrm{B}, \mathrm{C})$, and $\mathrm{Fe}_{3} \mathrm{C}$ after thermal annealing for 30 min. at $729 \mathrm{~K}$ [6].

1. T. F. Kelly and D. J. Larson, Annual Reviews of Materials Research 42 (2012) 1.

2. H. Takamizawa et al., Applied Physics Letters 100 (2012) 253504.

3. J. W. Valley et al., Abstracts American Geophysical Fall Meeting (2012) V12A-05.

4. $\quad$ A. D. Giddings et al., Phys. Rev. B 83 (2011) 205308.

5. $\quad$ L. M. Gordon, L. Tran and D. Joester, ACS Nano 6(12) 201210667.

6. Part of this research was sponsored by ORNL's Shared Research Equipment (ShaRE) User Facility, which is sponsored by the Scientific User Facilities Division, Office of Basic Energy Sciences, US Department of Energy. 


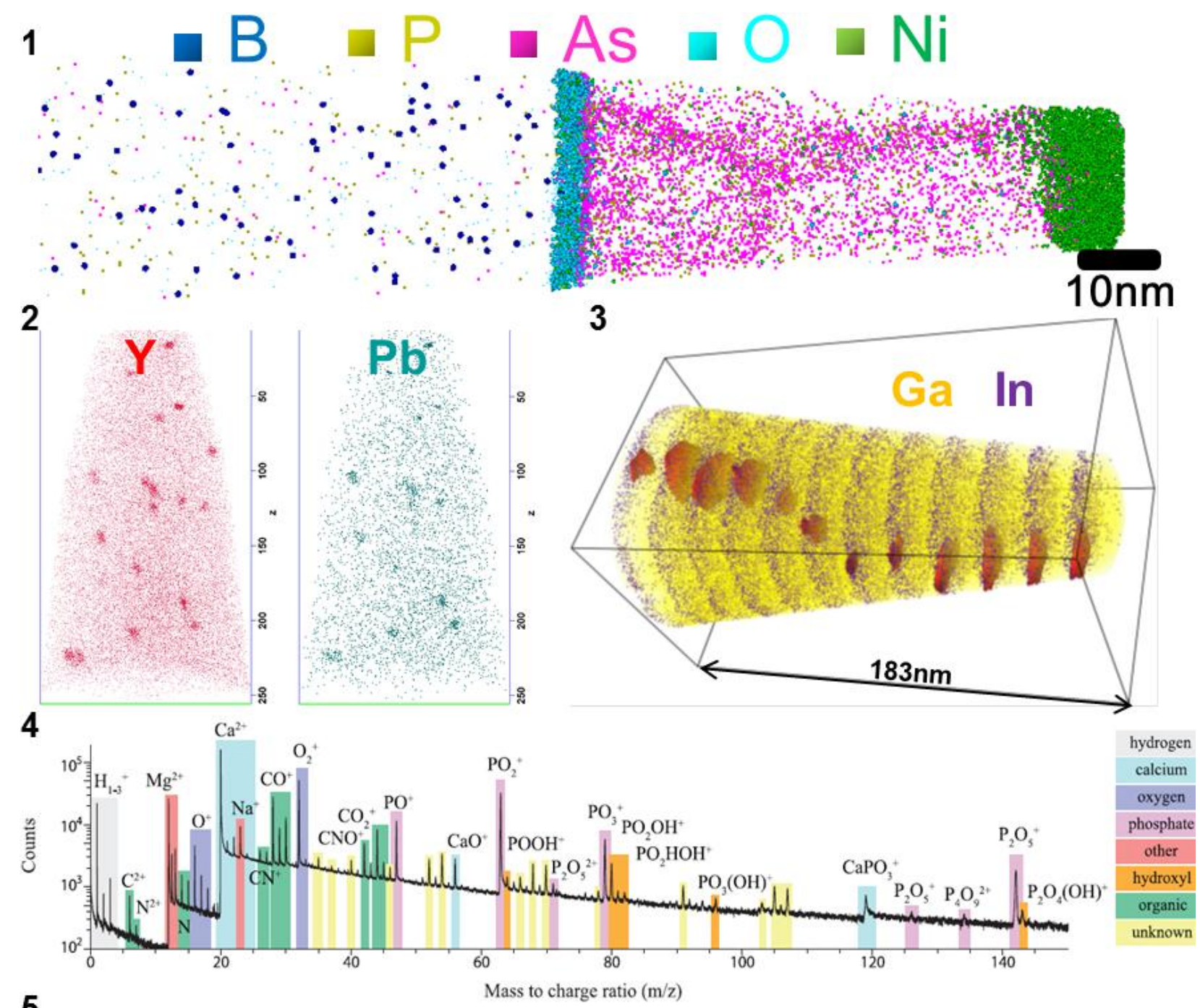

5

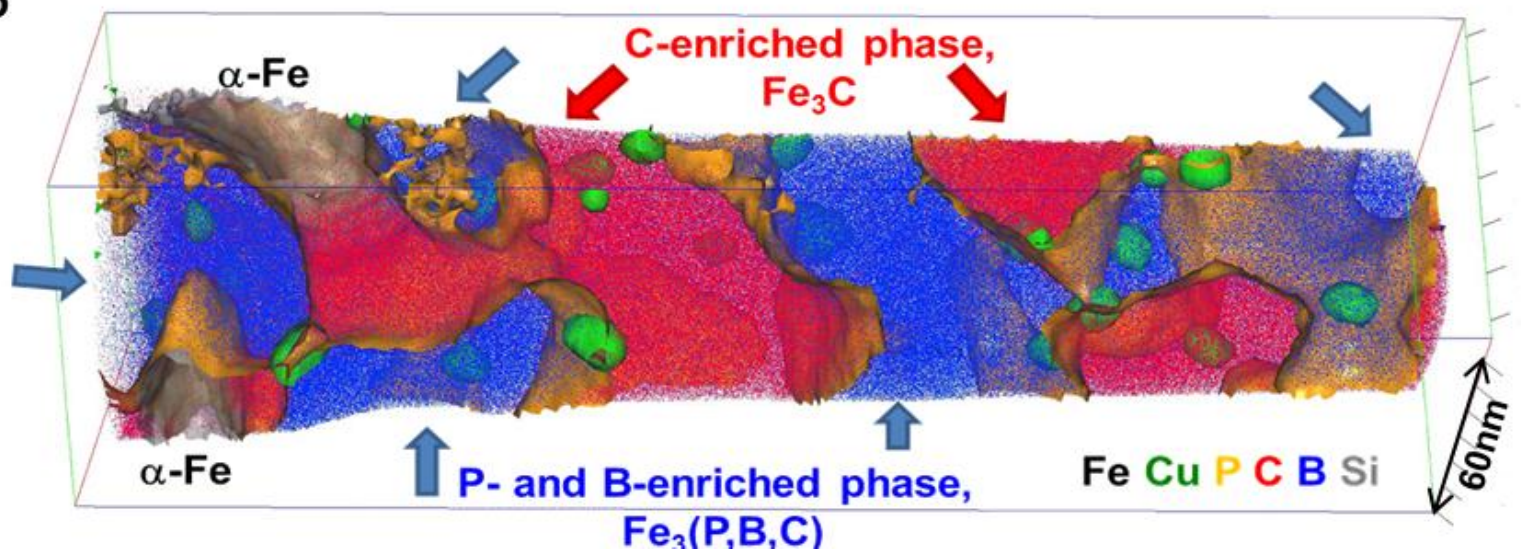

FIG. 1. Atom map showing the dopant distribution in a MOS transistor.

FIG. 2. Atom maps showing the $\mathrm{Y}$ and $\mathrm{Pb}$ distribution in a zircon.

FIG. 3. Atom map showing the arrangement of QDs (highlighted by red iso-concentration surfaces). FIG. 4. Mass spectrum from elephant tusk dentin.

FIG. 5. Atom map with various composition surfaces highlighting the complex nano-structure observed in this particular metallic glass. 